\title{
Development and Validation of a Questionnaire to Measure Medication Adherence to Direct-Acting Agents in Patients with Hepatitis C
}

\author{
Adina Turcu-Stiolica ${ }^{1}$, Irina Paula Doica ${ }^{2, *}$, Bogdan Silviu Ungureanu ${ }^{2, *} \mathbb{1}$, Ion Rogoveanu ${ }^{2}$, \\ Dan Nicolae Florescu ${ }^{2}$, Mihaela-Simona Subtirelu ${ }^{1}$ and Dan Ionut Gheonea ${ }^{2}$ \\ 1 Pharmacoeconomics Department, University of Medicine and Pharmacy of Craiova, 200349 Craiova, \\ Romania; adina.turcu@umfcv.ro (A.T.-S.); mihaela.subtirelu@umfcv.ro (M.-S.S.) \\ 2 Gastroenterology Department, University of Medicine and Pharmacy of Craiova, 200349 Craiova, Romania; \\ ion.rogoveanu@umfcv.ro (I.R.); dan.florescu@umfcv.ro (D.N.F.); dan.gheonea@umfcv.ro (D.I.G.) \\ * Correspondence: doicairinapaula@gmail.com (I.P.D.); bogdan.ungureanu@umfcv.ro (B.S.U.)
}

Citation: Turcu-Stiolica, A.; Doica, I.P.; Ungureanu, B.S.; Rogoveanu, I.; Florescu, D.N.; Subtirelu, M.-S.; Gheonea, D.I. Development and Validation of a Questionnaire to Measure Medication Adherence to Direct-Acting Agents in Patients with Hepatitis C. Pharmaceutics 2021, 13, 1683. https://doi.org/10.3390/ pharmaceutics13101683

Academic Editors: Przemysław Kardas and George P. Patrinos

Received: 6 September 2021

Accepted: 12 October 2021

Published: 14 October 2021

Publisher's Note: MDPI stays neutral with regard to jurisdictional claims in published maps and institutional affiliations.

Copyright: (c) 2021 by the authors. Licensee MDPI, Basel, Switzerland. This article is an open access article distributed under the terms and conditions of the Creative Commons Attribution (CC BY) license (https:// creativecommons.org/licenses/by/ $4.0 /)$.

\begin{abstract}
This study aims to develop a new self-report tool (HCV-AD) measuring adherence factors, intentional or unintentional, during Hepatitis C Virus (HCV) treatment with direct-acting antivirals (DAA) aiming to achieve high efficacy, otherwise resulting in drug resistance and treatment failure. Two phases were conducted: in the first phase, items were generated based on an extensive literature review, and, in the second phase, a prospective cohort study was conducted using HCV patients from Gastroenterology Department from University County Hospital of Craiova, Romania $(\mathrm{n}=222)$, to evaluate the validity and reliability of the questionnaire. A number of 19 items were generated following a systematic review and through expert opinion. The internal consistency reliability was evaluated using Cronbach's alpha. The construct validity was assessed using correlations with two other instruments: visual analog scale (VAS) and medication possession ratio (MPR). The final questionnaire (HCV-AD10) was derived through exploratory factor analysis, with $82 \%$ of total variance explained. This instrument appeared as a reliable and valid measure for medication adherence, with Cronbach's alpha (0.867) and significant high positive correlations between adherence scores calculated with HCV-AD10 and VAS $(\varrho=0.61, p<0.001)$ or with HCV-AD10 and MPR $(\varrho=0.75$, $p<0.001)$. This research would make a worthwhile contribution to HCV management.
\end{abstract}

Keywords: adherence in hepatitis C; direct-acting antivirals; development and validation

\section{Introduction}

Direct-acting antivirals (DAA) have resulted in path breaking development of hepatitis $\mathrm{C}$ virus (HCV) management [1]. HCV was discovered just before the 1990s [2] and similar to other gastrointestinal diseases which might be preventable by other techniques [3], determining its serology and replication became essential for everyday practice, especially for patients receiving blood transfusions. The World Health Organization (WHO) target of HCV elimination in European Countries [4] seems rather feasible, as many countries have focused their attention on micro-screening [5] and extended the panel of DAA to cover all possible downsizing, such as phenotypic variation or medication adherence [6]. While they are well tolerated, with a course of therapy of 12 weeks depending on the fibrosis stage, their action is still related to medication adherence [7].

HCV management with DAA lacks in measurements studies, with only a few evidencebased methods included so far. Medication adherence is known to be influenced by negative perceptions about medication, poor knowledge, high costs or fear of possible side effects [8]. While the era of interferon regimens focused on these issues, the new DAA may face a challenge in specific situations due to the psychosocial or socio-economic burden that HCV patients may encounter [9]. In addition, promoting new medication for patients 
who underwent interferon therapy and had severe side effects might make them reluctant at first.

Despite the high success of therapy, DAA agents still require valid tools to assess their adherence in clinical practice. The threshold of $80 \%$ has been used to characterize a good adherence since 1976 [10], but a new threshold must be defined for various therapeutic areas [11], being clearly questioned as a general standard [12]. As there is no documented standard of DAA adherence to obtain cure rates [13], a new valid and clinically useful threshold could be established for DAA non-adherence from which a patient no longer could have good outcomes in HCV treatment. Studies so far have focused on pill counts (PC) [14], the use of Visual Analog Scale (VAS) [15] and mostly pharmacy records [16,17], which help to construct a general idea in specific situations over medication adherence. The number of wireless pillbox openings or video-recorded ingestions was used for DAA adherence monitoring [18]. However, other factors should be considered too, such as previous treatment experience, which may generate medication administration fear, as well as multi-tablet therapy by adding more medication to their previous treated comorbidities [19]. Moreover, the concept of medication possession ratio (MPR) does not cover the period when patients might discontinue their therapy earlier than described [20].

The aim of our study is to develop a reliable and valid adherence self-report tool, easy to administer on a large scale, while attending to the main limitations of currently used tools in DAA adherence of HCV patients.

\section{Materials and Methods}

Within a prospective study on HCV patients, we developed a new tool for assessing self-reported adherence, by starting with item generation and content validity, followed by a preliminary questionnaire development, and concludes with a rigorous scientific evaluation, succeeding by implementing the following steps: pilot testing, data collection (sampling and survey administration), item reduction analysis and evaluation [21,22]. Data on socio-demographic patient characteristics, education, employment, and income, were obtained at baseline. Medication-related beliefs, evaluated as factors potentially associated with non-adherence, were collected at 30 days post the DAA treatment. The study was approved by the Ethics Committee of the University of Medicine and Pharmacy of Craiova, Romania (no. 87/12.02.2020).

\subsection{Generation of the $H C V-A D$ Items}

The items of the questionnaire used for DAA adherence assessment in HCV patients (HCV-Adherence, HCV-AD) were proposed based on a prior literature review of selfreported adherence, followed by a careful analysis of the content validity by two experts (B.S.U. and A.T-S.). We included many items to better capture all the factors influencing medication adherence. The questions were arranged and reworded in order to eliminate ambiguity, and technical jargon. A pilot testing of the proposed instrument was conducted in the next step in the target population (a sample of $30 \mathrm{HCV}$ patients).

\section{2. $H C V$-AD Evaluation}

The Kaiser-Meyer-Olkin (KMO) criterion was applied for testing the appropriate sample size. The determinant and Bartlett's test of sphericity were used to establish the stability of the factors. Reliability and validity were evaluated. Factors were extracted and optimized through Exploratory Factor Analysis (EFA). Kaiser's criterion and Cattell's scree plot were used, a factor with more than one eigenvalue was retained after the elbow indicated the cut-off point for factor extraction. Internal consistency was assessed through Cronbach's alpha $(\alpha)$ coefficient. Construct validity was demonstrated by correlation matrices of associations between HCV-AD score and two other instruments measuring adherence: VAS and MPR. The VAS recorded the respondent's self-related adherence where the endpoints are labelled " $100 \%$ adherent" and " $0 \%$ adherent", being a quantitative measure of medication adherence as judged by the individual respondents. We used 
individual patient data reported by community pharmacies at the Health Insurance House, following the legal requirements on personal data protection, to calculate the medication adherence with MPR formula:

$$
\text { Adherence }=\frac{\sum \text { tablets dispersed }}{\sum \text { tablets prescribed }}
$$

\subsection{Sample}

Patients with detectable RNA-HCV at baseline, regardless of the value, were considered eligible. We did not exclude patients which followed previous treatment with interferon, which either did not respond to treatment or were or stopped the treatment due to side effects. We excluded individuals with HIV- coinfection, or recently diagnosed with malignancies.

A total of 236 were enrolled across the University County Hospital of Craiova, Romania, from March 2020 to April 2021, as in Figure 1. Of the eligible HCV patients, 4 refused DAA treatment, 8 refused to participate, and 2 patients were lost to follow-up.

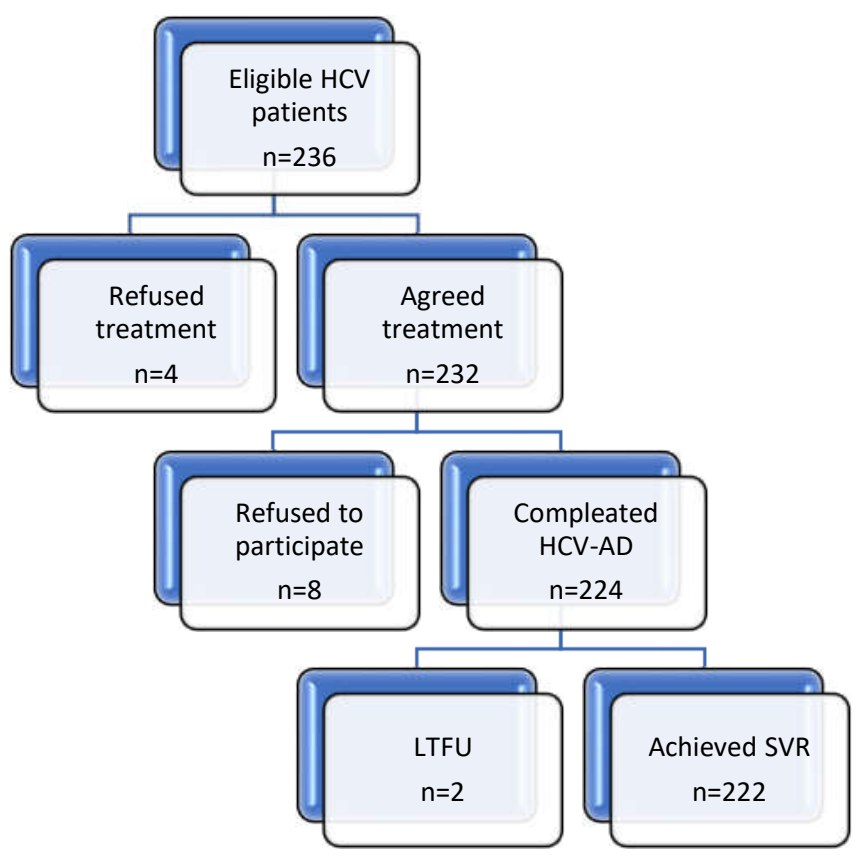

Figure 1. Study design and participant flow. HCV, hepatitis C virus; HCV-AD, the medication adherence questionnaire; LTFU, lost to follow-up; SVR, sustained virologic response.

\subsection{Statistical Analysis}

Continuous variables were expressed as means (standard deviation), and categorical variables as frequencies (percentage). Data management and analysis, and exploratory factor analysis (EFA) were done using GraphPad Prism 9.1.0 (GraphPad Software, San Diego, CA, USA). Prior to the extraction of the factors, Kaiser-Meyer-Olkin (KMO) Measure of Sampling Adequacy and Bartlett's Test of Sphericity were determined. A KMO index of 0.5 and significant Bartlett's test of sphericity $(p<0.01)$ were considered suitable for factor analysis [23]. Parallel analysis was conducted using EFA.dimensions package in $\mathrm{R}$ software ( $\mathrm{R}$ foundation, Vienna, Austria). Once the final model was determined, the internal consistency was tested using Cronbach's $\alpha$ and McDonald's Omega [24] using the MBESS package in R software [25,26]. The threshold of $>0.8$ was considered as having high internal consistency ( $>0.7$ is a good consistency, $<0.7$ is considerably questionable). Convergent validation of the questionnaire was examined using Spearman correlation coefficients. A $p$-value less than 0.05 was considered statistically significant. 


\section{Results}

The paper-based questionnaire with 20 initial items was administered for pre-testing in the pilot step to 30 patients with HCV to assess item clarity and to estimate the reliability. Patients confirmed items as readable and accurate in reflecting the factors influencing medication adherence. One item was dropped for lack of importance. Items were positively stated with three exceptions (Q11, Q12, Q18); the negatively stated items were reverse coded.

The range for completing the survey was between 5 and $10 \mathrm{~min}$.

A sample of $222 \mathrm{HCV}$ patients completed all survey items, including $25 \%$ were male. More details about the sample characteristics can be seen in Table 1.

Table 1. Baseline characteristics of patients.

\begin{tabular}{|c|c|}
\hline Characteristics & Patients $(n=222)$ \\
\hline Age in years, mean (SD) & $60.8(12.1)$ \\
\hline Gender-Male, n (\%) & $56(25.2 \%)$ \\
\hline \multicolumn{2}{|l|}{ Education } \\
\hline Elementary school & $114(51.4 \%)$ \\
\hline High school & $88(39.6 \%)$ \\
\hline Faculty & $20(9.0 \%)$ \\
\hline \multicolumn{2}{|l|}{ Marital status } \\
\hline Married & $162(73 \%)$ \\
\hline Single, never married & $12(5.4 \%)$ \\
\hline Widowed & $40(18 \%)$ \\
\hline Divorced & $8(3.6 \%)$ \\
\hline \multicolumn{2}{|l|}{ Environmental } \\
\hline Urban & $92(41.4 \%)$ \\
\hline Rural & $130(58.6 \%)$ \\
\hline \multicolumn{2}{|l|}{ Employment status } \\
\hline Employed & $64(28.8 \%)$ \\
\hline Unemployed & $14(6.3 \%)$ \\
\hline Social help & $6(2.7 \%)$ \\
\hline Retired & $138(62.2 \%)$ \\
\hline \multicolumn{2}{|l|}{ Income } \\
\hline$<2000 \mathrm{RON}$ & $186(94.6 \%)$ \\
\hline $2000-4000$ RON & $34(15.3 \%)$ \\
\hline $4000-6000$ RON & $2(0.90 \%)$ \\
\hline$>6000 \mathrm{RON}$ & 0 \\
\hline \multicolumn{2}{|l|}{ Smoking } \\
\hline Former smoker & $44(19.8 \%)$ \\
\hline Smoker & $24(10.8 \%)$ \\
\hline Never smoker & $154(69.4 \%)$ \\
\hline \multicolumn{2}{|l|}{ HCV genotype } \\
\hline $3 b$ & $222(100 \%)$ \\
\hline HCV duration in years, mean (SD) & $6.59(6.9)$ \\
\hline \multicolumn{2}{|l|}{ Treatment regimen } \\
\hline Ledipasvir/sofosbuvir & $152(68.5 \%)$ \\
\hline Dasabuvir/ombitasvir/paritaprevir/ritonavir & $70(31.5 \%)$ \\
\hline \multicolumn{2}{|l|}{ Treatment duration, $\mathrm{n}(\%)$} \\
\hline 8 weeks & $112(50.5 \%)$ \\
\hline 12 weeks & $110(49.5 \%)$ \\
\hline SVR, sustained virologic response & $222(100 \%)$ \\
\hline \multicolumn{2}{|l|}{ Fibrosis stage, $\mathrm{n}(\%)$} \\
\hline F0 & $28(12.6 \%)$ \\
\hline F0-F1 & $10(4.50 \%)$ \\
\hline F1 & $18(8.1 \%)$ \\
\hline F1-F2 & $36(16.2 \%)$ \\
\hline F2 & $26(11.7 \%)$ \\
\hline F2-F3 & $2(0.9 \%)$ \\
\hline F3 & $18(8.1 \%)$ \\
\hline F3-F4 & $10(4.5 \%)$ \\
\hline $\mathrm{F} 4$ & $74(33.3 \%)$ \\
\hline
\end{tabular}

\subsection{Exploratory Factor Analysis}

The initial questionnaire proposed 19 items (Table 2) with five response options (also called the five-point Likert scale, ranked from "Strongly disagree" to "Strongly agree" (Q5, 
Q6, Q17) or from “Never" to "Very often" (Q1-Q4, Q7-Q16). The last question Q19 has "yes/no" answers. Every item has the score from 5 to 1 .

Table 2. The HCV-AD19.

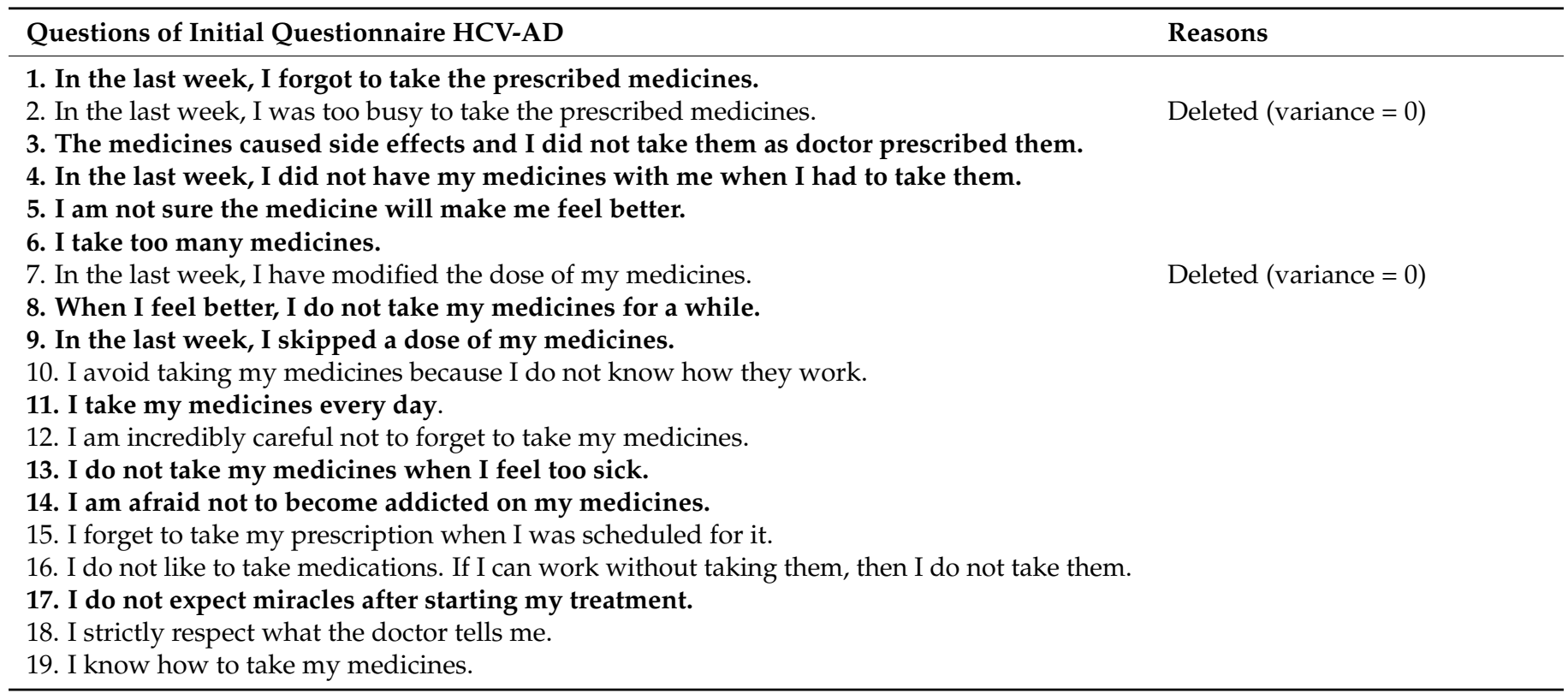

Final items of HCV-AD were bolded.

An EFA was used to reduce the items to a more parsimonious set for measuring DAA adherence for HCV patients. Two questions were deleted (Q2 and Q7) because their variance was null. The sample size measure through KMO (0.834) and Bartlett's test of sphericity $(p<0.001)$ confirmed that the item scores were suitable for factor analysis.

In the first round of EFA, the responses on the 17 items of $\mathrm{HCV}$-AD were intercorrelated and rotated to an orthogonal solution. The eigenvalues and the scree plot (Figure 2) were examined, providing a number of five factors represented by the data, which were verified also with parallel analysis (Table 3).

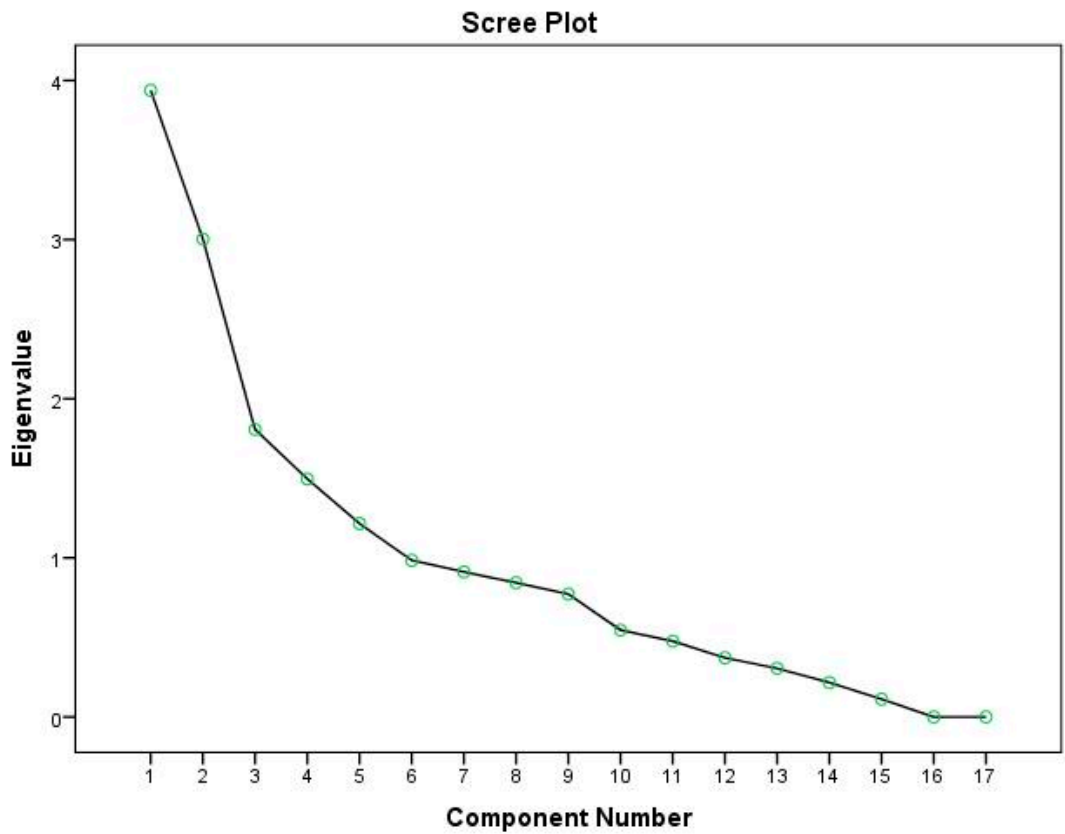

Figure 2. Scree plot of Exploratory Factor Analysis. 
Table 3. The total variance explained with Eigenvalues using EFA.

\begin{tabular}{|c|c|c|c|c|c|c|c|}
\hline \multirow{2}{*}{ Factor } & \multicolumn{3}{|c|}{ Initial Eigenvalues } & \multicolumn{3}{|c|}{ Rotation Sums of Squared Loadings } & \multirow{2}{*}{$\begin{array}{c}\text { Means from } \\
\text { Parallel Analysis }\end{array}$} \\
\hline & Total & $\%$ of Variance & Cumulative \% & Total & $\%$ of Variance & Cumulative \% & \\
\hline 1 & 3.94 & 23.17 & 23.17 & 3.17 & 18.64 & 18.64 & 1.5218 \\
\hline 2 & 3.00 & 17.67 & 40.73 & 2.3 & 13.55 & 32.19 & 1.4069 \\
\hline 3 & 1.81 & 10.63 & 51.46 & 2.17 & 12.78 & 44.97 & 1.3319 \\
\hline 4 & 1.5 & 8.8 & 60.26 & 2.09 & 12.3 & 57.27 & 1.2555 \\
\hline 5 & 1.22 & 7.15 & 67.41 & 0.72 & 10.14 & 67.41 & 1.1949 \\
\hline 6 & 0.98 & 5.79 & 73.2 & & & & 1.1346 \\
\hline 7 & 0.91 & 5.36 & 78.56 & & & & 1.0779 \\
\hline 8 & 0.84 & 4.96 & 83.53 & & & & 1.0261 \\
\hline 9 & 0.77 & 4.54 & 88.07 & & & & 0.9757 \\
\hline 10 & 0.55 & 3.21 & 91.28 & & & & 0.9253 \\
\hline 11 & 0.48 & 2.8 & 94.09 & & & & 0.8789 \\
\hline 12 & 0.37 & 2.19 & 96.27 & & & & 0.8345 \\
\hline 13 & 0.31 & 1.79 & 98.07 & & & & 0.7889 \\
\hline 14 & 0.22 & 1.27 & 99.34 & & & & 0.744 \\
\hline 15 & 0.11 & 0.66 & 100 & & & & 0.6918 \\
\hline 16 & $4.8^{*} 10^{-33}$ & $2.8^{*} 10^{-32}$ & 100 & & & & 0.6418 \\
\hline 17 & $-9.6^{*} 10^{-17}$ & $-5.7^{*} 10^{-16}$ & 100 & & & & 0.5692 \\
\hline
\end{tabular}

Next, the items included in the extracted five factors were reviewed. Factors with less than three items were removed to ensure that each factor was well measured. Reliability was assessed for every factor: if Cronbach's $\alpha$ was greater than 0.7 , all the items remained into that factor. Factor $1(\mathrm{Q} 1, \mathrm{Q} 3, \mathrm{Q} 4, \mathrm{Q} 9)$ had $\alpha=0.888$ and we included them in the final questionnaire. Factor $2(\mathrm{Q} 5, \mathrm{Q} 16, \mathrm{Q} 17, \mathrm{Q} 18)$ had $\alpha=0.681$ and after Q16 and Q18 were deleted, $\alpha=0.732$. Factor $3(\mathrm{Q} 6, \mathrm{Q} 12, \mathrm{Q} 14)$ had $\alpha=0.720$ and after Q12 was deleted, $\alpha=0.864$. Factor 4 (Q8, Q11, Q13) had $\alpha=0.786$ and after Q11 was deleted, $\alpha=0.831$. Factor 5 contained only two items (Q10, Q15). The other items were not included in factors.

The analysis yielded three factors that accounted for $70 \%$ of the total variance with Factor 1 explaining $31.55 \%$ of the variance whereas Factor 2 explaining $24.8 \%$, as seen in Table 4 .

Table 4. The total variance explained with Eigen values for the HCV-AD10.

\begin{tabular}{|c|c|c|c|c|c|c|}
\hline \multirow{2}{*}{ Factor } & \multicolumn{3}{|c|}{ Initial Eigenvalues } & \multicolumn{3}{|c|}{ Rotation Sums of Squared Loadings } \\
\hline & Total & $\%$ of Variance & Cumulative \% & Total & $\%$ of Variance & Cumulative \% \\
\hline 1 & 3.28 & 32.77 & 32.77 & 3.16 & 31.55 & 31.55 \\
\hline 2 & 2.47 & 24.73 & 57.51 & 2.48 & 24.8 & 56.35 \\
\hline 3 & 1.29 & 12.95 & 70.45 & 1.41 & 14.10 & 70.45 \\
\hline 4 & 0.94 & 9.44 & 79.89 & & & \\
\hline 5 & 0.86 & 8.55 & 88.44 & & & \\
\hline 6 & 0.56 & 5.63 & 94.07 & & & \\
\hline 7 & 0.46 & 4.59 & 98.66 & & & \\
\hline 8 & 0.13 & 1.34 & 100 & & & \\
\hline 9 & $1.4^{*} 10^{-33}$ & $1.4^{*} 10^{-32}$ & 100 & & & \\
\hline 10 & $-7.8^{*} 10^{-17}$ & $-7.8^{*} 10^{-16}$ & 100 & & & \\
\hline
\end{tabular}


As in Table 5, the three subscales that emerged from the EFA represent the areas of medication adherence: unintended factors (forgetting to take or to have the drugs when they had to take them), fear of the drugs, the intended factors (if the patients feel sick or better, they do not take the drugs).

Table 5. Factor loadings for the survey items after Exploratory Factor Analysis.

\begin{tabular}{lc}
\hline \multicolumn{1}{c}{ Survey Item } & Subscale (Factors) \\
\cline { 2 - 2 } & $\mathbf{1}$ \\
\hline 1. In the last week, I forgot to take the prescribed medicines. & 0.887 \\
3. The medicines caused side effects and I did not take them as the doctor prescribed them. & 0.887 \\
4. In the last week, I did not have my medicines with me when I had to take them. & 0.883 \\
9. In the last week, I skipped a dose of my medicines. & 0.883 \\
5. I am not sure the medicine will make me feel better. & 0.773 \\
17. I do not expect miracles after starting my treatment. & 0.712 \\
6. I take too many medicines. & 0.853 \\
14. I am afraid not to become addicted to my medicines. & 0.787 \\
8. When I feel better, I do not take my medicines for a while. & 0.846 \\
13. I do not take my medicines when I feel too sick. & 0.813 \\
\hline
\end{tabular}

The adherence score after applying the 10-items HCV-AD will be calculated as the sum of all scored items minus 10 and divided by 0.40 :

$$
\mathrm{HCV}-\mathrm{AD} 10 \text { score }=\frac{\sum_{i=1}^{10} Q i-10}{0.40}
$$

\subsection{Internal Consistency}

In the total sample, the Cronbach's alpha coefficient for the total HCV-AD10 was 0.867 and item-total correlations ranged from 0.17 to 0.79 . None of the 10 final items could be deleted without a decrease in Cronbach's alpha. The McDonald's omega value ( $\omega=0.877)$ confirmed that the HCV-AD10 is high.

\subsection{Construct Validity}

To investigate whether HCV-AD10 captures medication adherence, we examined the correlations (Spearman's $\varrho$ ) between the obtained scores and VAS and MRP scores. Descriptive statistics of adherence scores are presented in Table 6.

Table 6. Adherence scores calculated with the used scales.

\begin{tabular}{cccc}
\hline \multirow{2}{*}{ Adherence Scales } & \multicolumn{3}{c}{ Adherence Scores } \\
\cline { 2 - 4 } & Mean & SD & Range \\
\hline HCV-AD19 & 93.99 & 5.63 & $80.26-100$ \\
HCV-AD10 & 91.53 & 8.42 & $72.5-100$ \\
VAS & 9.78 & 0.49 & $8-10$ \\
MPR & 96.7 & 4.93 & $87.5-100$ \\
\hline
\end{tabular}

HCV-AD19, the initial questionnaire with 19 items; HCV-AD10, the final questionnaire with 10 items; VAS, visual analog scale; MPR, medication possession ratio.

Spearman's correlation analysis demonstrated significant positive correlations between adherence scores calculated with HCV-AD10 (SCORE10) and VAS $(\varrho=0.61, p<0.001)$ or with HCV-AD10 and MPR $(\varrho=0.75, p<0.001)$, as shown in Figure 3. 


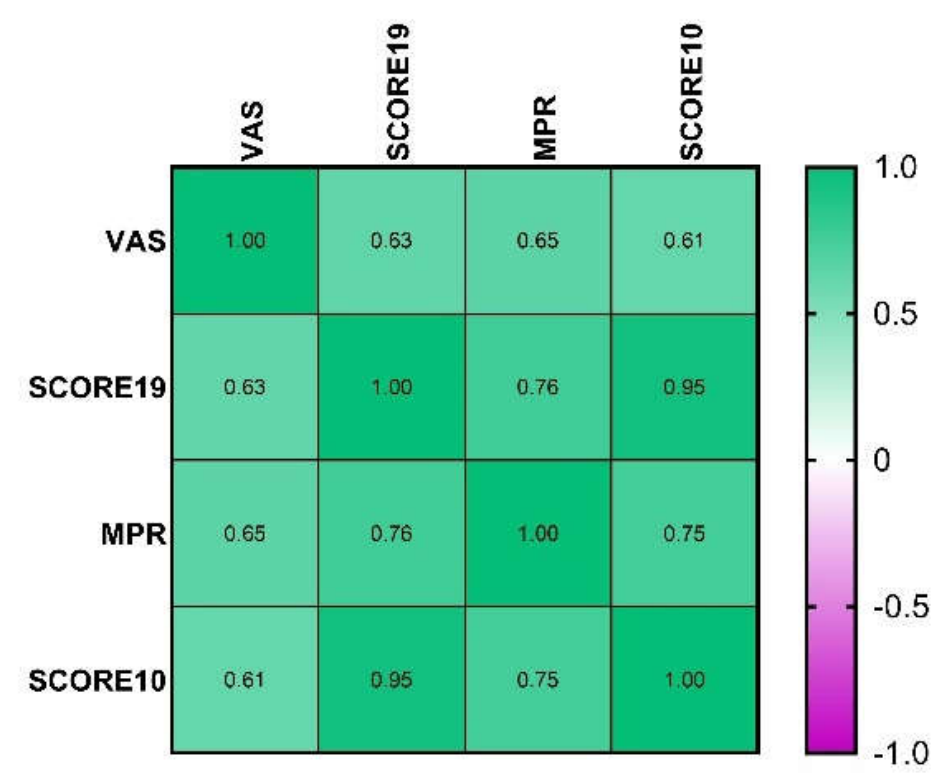

Figure 3. Heatmap containing Spearman coefficients with values from -1 to 1 , as the colours from the right show, larger values were represented by dark green and smaller values by dark mauve. SCORE10, the adherence score calculated with HCV-AD10; SCORE19, the adherence score calculated with HCV-AD19.

\section{Discussion}

Our HCV-AD10 questionnaire has good construct validity, supporting its adequacy for jeopardizing the effectiveness of DAA therapy in patients with HCV. To the best of our knowledge, this is the first questionnaire trying to understand the factors expression which facilitates or sabotages medication adherence in patients with $\mathrm{HCV}$ when DAA are used. The other tools used to assess the DAA adherence did not reveal why the patients do not adhere to the prescribed treatment. Serper et al., assessed the DAA adherence for HCV considering non-adherence being the absence of lab results after DAA therapy completion [27]. However, taking medication is a complex behaviour and pharmacy refill analysis is not practical due to the short duration of the treatment.

Butt et al., demonstrated that the efficacy of sofosbuvir-based treatment regimens was not affected when patients were nonadherent [28]. Even though this new line of therapy used for HCV has overcome the boundaries of interferon regimens, the path for HCV eradication might still require substantial tools to achieve high medication adherence. HCV-AD is a practical adherence method, easy to apply and might determine potential patients who may be reluctant to therapy.

We proposed a new instrument that might aid in identifying a specific group of patients, which might require extensive monitoring over their treatment time. DAA offer several advantages when administered. Currently, there are many available options that may cover all genotypes and might successfully lead to HCV elimination. If used, these pan-genotypic regimens might be very helpful for HCV eradication. Moreover, the fibrosis stage could also be considered an important factor for medication adherence as it may reduce pills administration from 12 to 8 weeks. The patients included in this study proved to have high medication adherence, which may be related to the single genotype and the fact that most patients were in a lower fibrosis stage, which means only 8 weeks of therapy. However, all these reasons might not be the actual main factors for medication adherence when using DAA for HCV treatment.

Most of the HCV patients could be reluctant at first, as they are more familiar with past interferon therapy which had significant side effects and also a low response rate. Perhaps the fear of the unknown for the new DAA might represent the most significant potential drawback when considering following medication, even if it is for a small period of time. The side effects of Interferon, as well as the use of new pills, might instate anxiety or fear of 
potential adverse reaction. Thus, identifying these types of risk patients could help prevent medication non-adherence. On the other hand, most of the patients with HCV present with other diseases which require extensive medication, which could require an extensive panel of medication per day. Adding more pills, even for a small amount of time, could confuse the elderly and make them even more unwilling to follow the treatment. Moreover, some DAAs may interact with patient's chronic medication, which might confuse them as they may need to replace some drugs during HCV eradication treatment. Hence, applying a targeted questionnaire could prevent some of these issues by focusing on specific aspects to encourage the patient to follow the DAA treatment.

We propose this new instrument to assess medication adherence on DAA, as it may provide a new perspective to include and understand even the most reluctant patients who for some reason might not follow the medication as indicated. Providing HCV-AD before treatment initiation could measure the patient's understanding of the DAA's risks and benefits and could lead to further explanation by the physician to overcome possible flaws. Our tool is a self-reported method which might be safely used to cover a rather short period of treatment either 8 or 12 months. It is inexpensive and according to our results serves as a reliable method to assess HCV patient's adherence. It is noteworthy that HCV-AD may not only be used only by prescribing physicians, but also by pharmacists, since studies have shown their potential role in medication adherence [17]. Involving a multidisciplinary team could raise patients trust and understanding of DAA for HCV management.

Our study also has several limitations. First, developing an HCV adherence tool should contain a diversity of patient's characteristics such as different genotypes, more types of DAA and a larger number of patients. Our cohort of HCV patients is rather inhomogeneous, with most of them being elderly and retired from work. This may be related to the fact that most of these patients did not address the previous national HCV therapy programs and were either found by micro screening programs or newly diagnosed on baseline analysis. Even though the specific DAA used in this study are still on the market, new DAA have been included and will be more frequently used since they will cover up all genotypes and be more safely used in specific patients such as the ones with end stage kidney disease, HIV associated disease or even children. On the other hand, all included patients were treated in a single medical centre. The 5-Likert rating scale, we chose, allows answers that are not undermined by forced completion and, also, the capacity to generate sufficient variance among the intended respondents. No tests of structural validity were performed, as the questions were not hypothesized to reflect latent dimensions of adherence. The DAA treatment is for a short period of time, with very promising outcomes, common reliability, and validity tests (e.g., Cronbach's $\alpha$ factor analysis) being very well applicable to stable behaviour [29].

Because all patients had SVR of 100\% we could not establish a threshold for DAA adherence. However, we are convinced that by having this instrument, future studies must be conducted to assess how small the adherence level can be, as not to achieve high virological response and sustained virological response.

This instrument might be a helpful tool in the WHO's objective of HCV eradication as it may cover some patients who may be non-adherent to therapy, exploring its predictors and finding strategies to promote DAA adherence.

\section{Conclusions}

Our developed HCV-AD10 is a validated and reliable instrument for evaluating adherence among HCV patients using the DAAs in Romania. It is simple to use and suitable to assess the patient-specific, illness-specific, or medication-related factors which are barriers to $\mathrm{HCV}$ eradication. 
Author Contributions: Conceptualization, A.T.-S. and B.S.U.; methodology, A.T.-S.; validation, I.P.D., I.R., D.N.F. and D.I.G.; formal analysis, A.T.-S.; resources, I.P.D., B.S.U., D.N.F. and M.-S.S.; data curation, I.P.D. and D.N.F.; writing-original draft preparation, A.T.-S. and B.S.U.; writing一review and editing, I.R. and D.I.G.; supervision, D.I.G. All authors have read and agreed to the published version of the manuscript.

Funding: The APC was funded by University of Medicine and Pharmacy of Craiova.

Institutional Review Board Statement: The study was conducted according to the guidelines of the Declaration of Helsinki, and approved by the Ethics Committee from the University of Medicine and Pharmacy of Craiova, Romania (no. 87/12.02.2020).

Informed Consent Statement: Informed consent was obtained from all subjects involved in the study.

Data Availability Statement: The datasets used and/or analyzed during the current study are available from the corresponding authors on reasonable request.

Conflicts of Interest: The authors declare no conflict of interest.

\section{References}

1. Shahid, I.; Ibrahim, M.M. All Oral Interferon-free Direct-acting Antivirals as Combination Therapies to Cure Hepatitis C. Curr. Mol. Med. 2018, 18, 409-435. [CrossRef] [PubMed]

2. Houghton, M. Hepatitis C Virus: 30 Years after Its Discovery. Cold Spring Harb. Perspect Med. 2019, 9, a037069. [CrossRef] [PubMed]

3. Popa, P.; Streba, C.T.; Calita, M.; Iovanescu, V.F.; Florescu, D.N.; Ungureanu, B.S.; Stanculescu, A.D.; Ciurea, R.N.; Oancea, C.N.; Georgescu, D.; et al. Value of endoscopy with narrow-band imaging and probe-based confocal laser endomicroscopy in the diagnosis of preneoplastic lesions of gastrointestinal tract. Rom. J. Morphol. Embryol. 2020, 61, 759-767. [CrossRef]

4. Dore, G.J.; Bajis, S. Hepatitis C Virus elimination: Laying the foundation for achieving 2030 targets. Nat. Rev. Gastroenterol. Hepatol. 2021, 18, 91-92. [CrossRef]

5. Butaru, A.E.; Doica, I.P.; Gheonea, D.I.; Rogoveanu, I.; Diculescu, M.; Oancea, C.N. Preliminary Results of the Micro-Elimination Project of Hepatitis C in a Disadvantaged Town in South-West of Romania-Orsova. Curr. Health Sci. J. 2020, 46, $217-221$.

6. Halfon, P.; Locarnini, S. Hepatitis C virus resistance to protease inhibitors. J. Hepatol. 2011, 55, 192-206. [CrossRef] [PubMed]

7. Ing Lorenzini, K.; Girardin, F. Direct-acting antiviral interactions with opioids, alcohol or illicit drugs of abuse in HCV-infected patients. Liver Int. 2020, 40, 32-44. [CrossRef]

8. Bowry, A.D.; Shrank, W.H.; Lee, J.L.; Stedman, M.; Choudhry, N.K. A systematic review of adherence to cardiovascular medications in resource-limited settings. J. Gen. Intern. Med. 2011, 26, 1479-1491. [CrossRef] [PubMed]

9. Meyer, J.P.; Moghimi, Y.; Marcus, R.; Lim, J.K.; Litwin, A.H.; Altice, F.L. Evidence-based interventions to enhance assessment, treatment, and adherence in the chronic Hepatitis C care continuum. Int. J. Drug Policy 2015, 26, 922-935. [CrossRef]

10. Haynes, R.B. A Critical Review of the "Determinants" of Patient Compliance with Therapeutic Regimens; Johns Hopkins University Press: Baltimore, MD, USA, 1976.

11. Burnier, M. Is There a Threshold for Medication Adherence? Lessons Learnt from Electronic Monitoring of Drug Adherence. Front. Pharmacol. 2019, 9, 1540. [CrossRef]

12. Baumgartner, P.C.; Haynes, R.B.; Hersberger, K.E.; Arnet, I. A Systematic Review of Medication Adherence Thresholds Dependent of Clinical Outcomes. Front. Pharmacol. 2018, 9, 1290. [CrossRef]

13. Bolduc, C.; McCall III, K.; Stickney, K.; Gelinas, A.; Levesques, E. Applicability of a new specialty pharmacy-reported measure describing completion of therapy for hepatitis C. J. Manag. Care Spec. Pharm. 2021, 27, 263-267.

14. Petersen, T.; Townsend, K.; Gordon, L.A.; Sidharthan, S.; Silk, R.; Nelson, A.; Gross, C.; Calderón, M.; Proschan, M.; Osinusi, A.; et al. High adherence to all-oral directly acting antiviral HCV therapy among an inner-city patient population in a phase $2 \mathrm{a}$ study. Hepatol. Int. 2016, 10, 310-319. [CrossRef] [PubMed]

15. Burton, M.J.; Voluse, A.C.; Patel, A.B.; Konkle-Parker, D. Measuring adherence to hepatitis C direct-acting antiviral medications: Using the VAS in an HCV treatment clinic. South Med. J. 2018, 111, 45-50. [CrossRef] [PubMed]

16. Walker, D.R.; Juday, T.R.; Manthena, S.R.; Jing, Y.; Sood, V. The impact of ribavirin on real-world adherence rates in hepatitis C patientstreated with sofosbuvir plus simeprevir. Clin. Outcomes Res. 2015, 7, 637-642.

17. Doica, I.P.; Florescu, D.N.; Oancea, C.N.; Turcu-Stiolica, A.; Subtirelu, M.S.; Dumitra, G.; Rogoveanu, I.; Gheonea, D.I.; Ungureanu, B.S. Telemedicine Chronic Viral Hepatitis C Treatment during the Lockdown Period in Romania: A pilot study. Int. J. Environ. Res. Public Health. 2021, 18, 3694. [CrossRef] [PubMed]

18. Brooks, K.M.; Castillo-Mancilla, J.R.; Morrow, M.; MaWhinney, S.; Rowan, S.E.; Wyles, D.; Blum, J.; Huntley, R.; Salah, L.M.; Tehrani, A.; et al. Adherence to Direct-Acting Antiviral Therapy in People Actively Using Drugs and Alcohol: The INCLUD Study. Open Forum Infect. Dis. 2020, 8, ofaa564. [CrossRef] [PubMed]

19. Taerel, A.E.; Turcu-Stiolica, A. Study on the range of drugs authorized in Romania-A determinant element for the accessibility and availability of drugs. Farmacia 2009, 57, 254-259. 
20. Pednekar, P.; Agh, T.; Melmenas, M.; Raval, A.; Bennett, B.; Borah, B.; Hutchins, D.; Manias, E.; Williams, A.; Hiligsmann, M.; et al. Methods for measuring multiple medication adherence: A systematic review-Report of the ISPOR medication adherence and persistence special interest group. Value Health 2019, 22, 139-156. [CrossRef]

21. Kishore, K.; Jaswal, V.; Kulkarni, V.; De, D. Practical guidelines to develop and evaluate a questionnaire. Indian Dermatol. Online J. 2021, 12, 266-275. [CrossRef]

22. Boateng, G.; Neilands, T.; Frongillo, E.; Melgar-Quinonez, H.; Young, S. Best Practices for Developing and Validating Scales for Health, Social, and Behavioral Research: A Primer. Front. Public Health 2018, 6, 149. [CrossRef] [PubMed]

23. Hair, J.; Anderson, R.E.; Tatham, R.L.; Black, W.C. Multivariate Data Analysis, 4th ed.; Prentice-Hall Inc.: New Jersey, NJ, USA, 1995.

24. McDonald, R.P. Test Theory: A Unified Treatment; Lawrence Erlbaum Associates, Inc.: New Jersey, NJ, USA, 1999.

25. Hayes, A.F.; Coutts, J.J. Use Omega rather than Cronbach's Alpha for Estimating Reliability. But ... . Commun. Methods Meas. 2020, 14, 1-24. [CrossRef]

26. Kelley, K. Methods for the behavioral, educational, and social sciences: An R package. Behav. Res. Methods 2007, 39, 979-984. [CrossRef] [PubMed]

27. Serper, M.; Evon, D.M.; Stewart, P.W.; Lok, A.S.; Amador, J.; Reeve, B.B.; Golin, C.E.; Fried, M.W.; Reddy, K.R.; Sterling, R.K.; et al. Medication Non-adherence in a Prospective, Multi-center Cohort Treated with Hepatitis C Direct-Acting Antivirals. J. Gen. Intern. Med. 2020, 35, 1011-1020. [CrossRef] [PubMed]

28. Butt, A.A.; Yan, P.; Shaikh, O.S.; Chung, B.T.; Sherman, K.E. Treatment adherence and virological response rates in hepatitis C virus infected persons treated with sofosbuvir-based regimens: Results from ERCHIVES. Liver Int. 2016, 36, 1275-1283. [CrossRef]

29. Dima, A.L.; van Ganse, E.; Laforest, L.; Texier, N.; de Bruin, M. \& the ASTRO-LAB group. Measuring medication adherence in asthma: Development of a novel self-report tool. Psychol. Health 2017, 32, 1288-1307. [CrossRef] [PubMed] 